\title{
Histopathological Examination in Bone Metastases
}

\author{
iD Bilge BíLGiç
}

Department of Pathology, Istanbul University, Istanbul Faculty of Medicine, Istanbul-Turkey

\section{Introduction}

Metastasis is the spread of malignant tumors from the place they first originated to distant organs, primarily by vascular route. Metastasis occurs commonly in lung, liver, and bone tissues. Metastatic tumors of the bone are more common than primary malignant tumors of the bone. The most frequently involved bones are the femur, humerus, and axial bones. Among bone metastases, carcinomas are the most common, and $80 \%$ are of lung, breast, prostate, kidney, and thyroid origin. Carcinomas are rarely followed by metastatic sarcomas (Ewing sarcoma, angiosarcoma (Fig. 1), alveolar soft part sarcoma, leiomyosarcoma, rhabdomyosarcoma, etc.), melanoma, and hematolymphoid malignancies. We can count neuroblastoma, clear cell sarcoma of the kidney, and nephroblastoma among metastatic malignancies in childhood. However, we rarely see bone metastases belonging to the medulloblastoma, one of the central nervous system tumors. [1-5]

Although metastasis reflects the advanced stage and the common disease state, various studies have shown that tumor cells enter the circulation very early, reach the bone marrow, stay "latent" for a long time and only grow and spread when they find a suitable environment.

On settlement of tumor cells in the bone marrow, we can count the properties of the endothelial layer of sinusoids, various factors released from tumor cells and their interaction with the stroma of the host tissue, and the relationship of osteocyte-osteoblasts and osteoclasts with substances released from the tumor cells. For example, in breast carcinoma, the presence of CXCR4 released from tumor cells and the stromal SDF1 ligand that interacts with these cells and enables them to attach to the host tissue can be seen. Again, PTH-

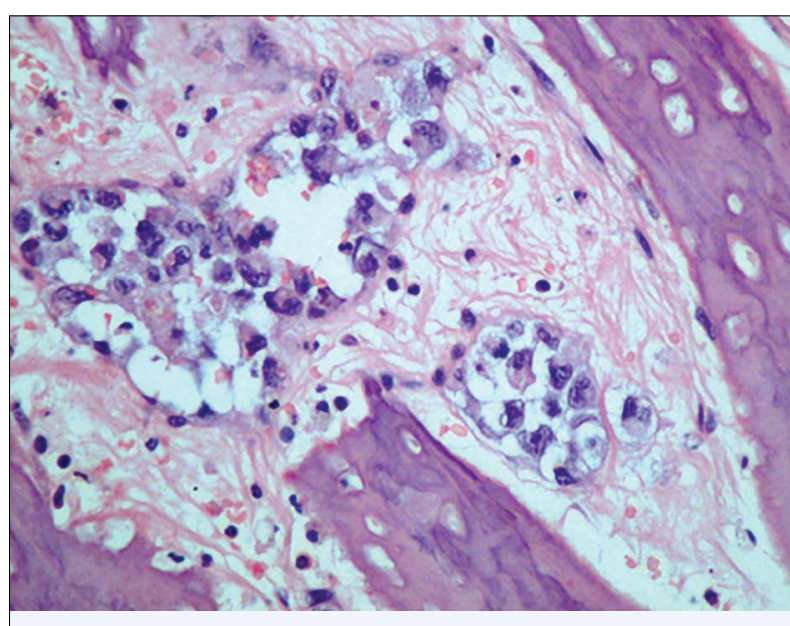

Fig. 1. Angiosarcoma metastasis between bone trabeculae HEx200.

related protein, various interleukins, and RANKL activation detected in breast carcinomas are responsible for osteoclastic stimulation, whereas PDGF and IGF growth factors are responsible for prostate carcinoma. It is seen that the presence of VEGFR1 in bone marrow cells contributes to the colonization of tumor cells in some areas of the bone marrow and forms groups, and the extracellular matrix proteins also play a role in this process. We also know that only some of the tumor cells that enter the bone marrow and remain latent for a long time can get activated, proliferated, and spread from there.[6-9]

When carcinoma metastasis is detected on the bone biopsy, the patient either has a concurrent or previous diagnosis of carcinoma or no history of malignancy, and the carcinoma is recognized by metastasis. On histopathological examination of the bone tissue, the morphological structure of the carcinoma gives us
Dr. Bilge BiLGiÇ

İstanbul Üniversitesi,

İstanbul Tıp Fakültesi,

Patoloji Anabilim Dalı,

Istanbul-Turkey

E-mail: bilge1963@gmail.com, bilge.bilgic@istanbul.edu.tr 
clues about the primary focus. If glandular structures of adenocarcinoma are present, it suggests lung tumors in the foreground, whereas if it is accompanied by mucin or colloidal material in the lumens, it suggests gastrointestinal tumors or thyroid tumors, respectively. The presence of keratin is an essential finding in favor of squamous cell carcinoma. Sometimes there is an appearance of undifferentiated carcinoma, and morphologically, the tumor does not give us any clue about its origin. An immunohistochemical examination is required to determine the primary source of origin of the tumor.[10,11] We look for various antigens in tumor cells in the immunohistochemical examination, and antibodies developed against these antigens are applied to unstained sections in an automated system to reveal them. We can see the staining that reveals a positive reaction in the tissue under the microscope on applying the appropriate antigen-antibody combinations. When we consider carcinoma metastasis in bone biopsy and do not know the primary focus, it is appropriate to start examining cytokeratin 7 and cytokeratin 20 antibodies. The probabilities are determined based on whether these two keratin subtypes are stained alone, together, or are both negative (Table 1). For example, when cytokeratin 7 is positive, lung and breast come to mind primarily, whereas when cytokeratin 20 is positive, it favors colorectal carcinoma metastasis. [10] Keratin subtypes only give us an approach but do not necessarily point to the primary source of origin; thus, it is necessary to expand the immune panel and apply organ-specific markers. For example, GATA3 and GCDFP markers for breast (Fig. 2), TTF1 for lung adenocarcinoma (Fig. 3) p40 for squamous cell carcinoma, Pax8, CD10 for kidney carcinoma (Figs. 4, 5) and CDX2 for colorectal carcinomas are administered, and the diagnosis is made (Table 2). When examining the primary tumor, considering that an antigen may be positive in different tumors, one should not rely on a single marker and be confirmed with more than one marker.

Occasionally, no origin for the primary tumor can be found despite large immune panels. The prognosis is generally lacking in these tumors reported as undifferentiated carcinoma. Sometimes, although diagnoses such as carcinoma, germ cell tumor, or melanoma metastasis are obtained in metastatic bone tissue, no focus can be seen when investigating the primary. This may be due to a very small primary focus that cannot be detected or show spontaneous or treatment-related regression. Another point to remember is that the primary tumor and metastasis are not always the same
Table 1 Cytokeratin 7/20 and types of carcinoma

\begin{tabular}{ll}
$\begin{array}{l}\text { Cytokeratin 7/20 } \\
\text { expression }\end{array}$ & Carcinoma type \\
\hline CK7 (+) CK20 (+) & Bladder, bile ducts \\
CK7 (+) CK20 (-) & Lung, breast, pancreas, thyroid, stomach \\
CK7 (-) CK20 (-) & Kidney, liver, prostate \\
CK7 (-) CK20 (+) & Colon-rectum \\
\hline
\end{tabular}

CK: Cytokeratin
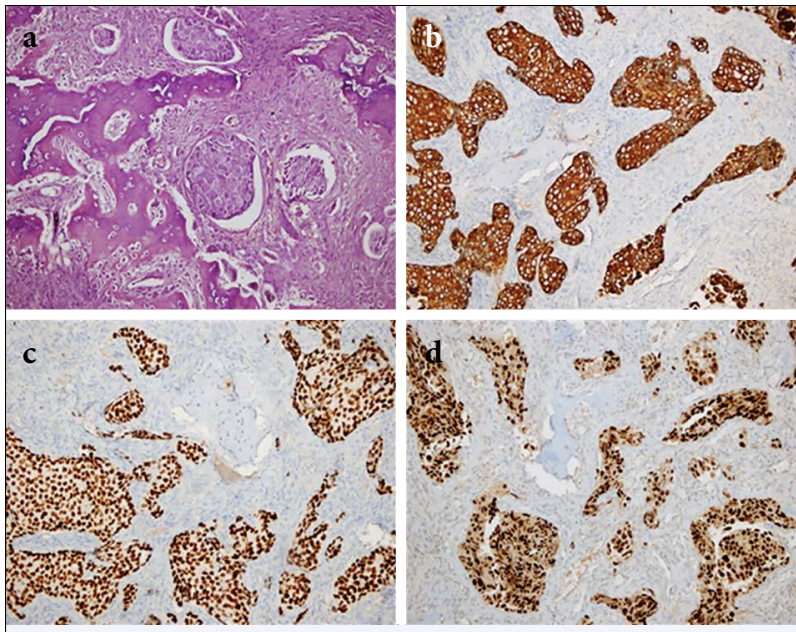

Fig. 2. HE (Hematoksilen-Eosin) (a), Cytokeratin 7 (b), Gata3 (c), and Estrogen receptor (d) positivity in breast carcinoma bone metastasis.
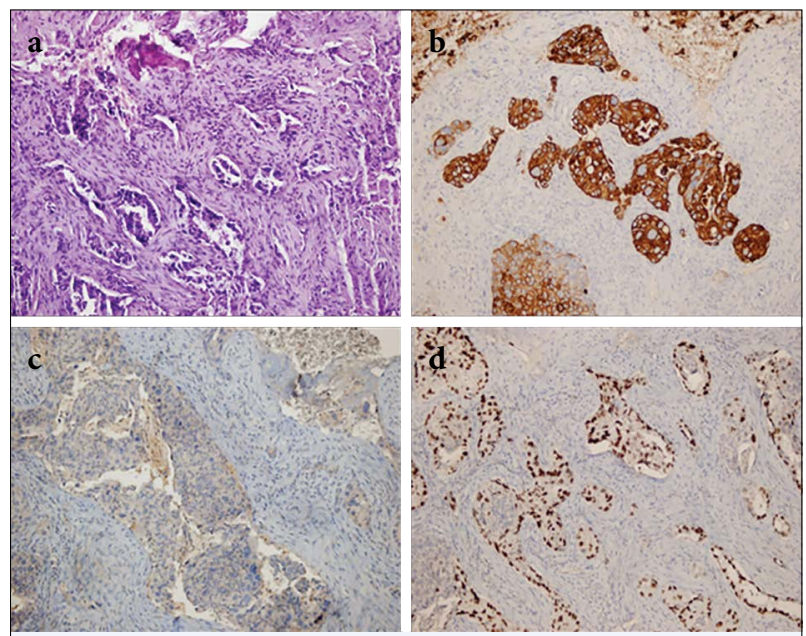

Fig. 3. HE (Hematoksilen-Eosin) (a), Cytokeratin 7 (b) positivity, Cytokeratin 20 (c) negativity, TTF1 (d) positivity in lung carcinoma bone metastasis.

morphologically, antigenically, or molecularly; because in malignant tumors, additional mutations and differ- 


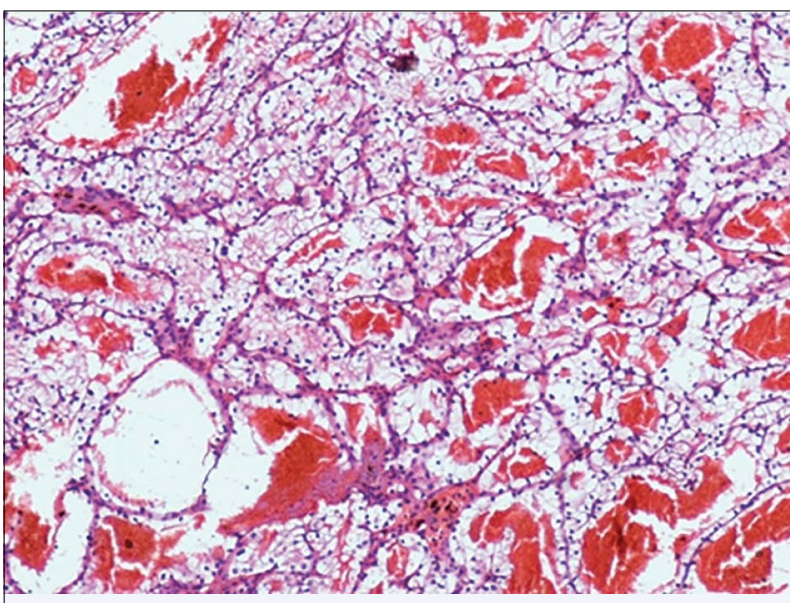

Fig. 4. Renal cell carcinoma HEx100.

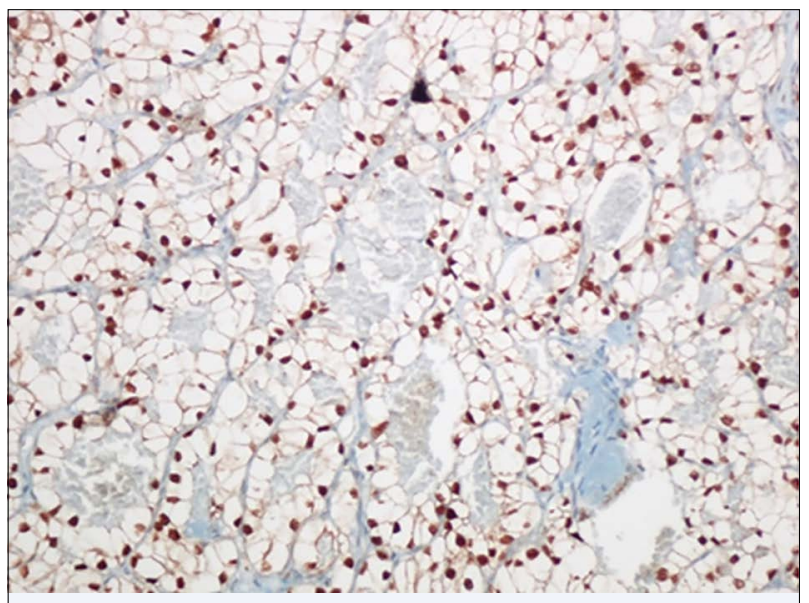

Fig. 5. Renal cell carcinoma PAX8 positivity x200.

Table 2 Immune markers in some types of carcinoma

\begin{tabular}{|c|c|}
\hline Carcinoma type & Immune marker \\
\hline Colorectal & CDX2, SATB2 \\
\hline Breast & GATA3, GCDFP, ER, PR, Mammaglobin \\
\hline Lung adenocarcinoma & TTF1, Napsin A \\
\hline $\begin{array}{l}\text { Squamous cell } \\
\text { carcinoma }\end{array}$ & p63, p40, Cytokeratin 5/6 \\
\hline Liver & $\begin{array}{l}\text { Arginase-1, HepPar-1, Glypican3, } \\
\text { pCEA }\end{array}$ \\
\hline Kidney & $\mathrm{PAX} 8, \mathrm{CD} 10$ \\
\hline Thyroid & PAX8, TTF1, Thyroglobulin \\
\hline
\end{tabular}

ent clones may develop over time and be reflected in the phenotype. Therefore, performing treatment and prognosis examinations in a new biopsy will reflect the current status of the tumor more accurately.

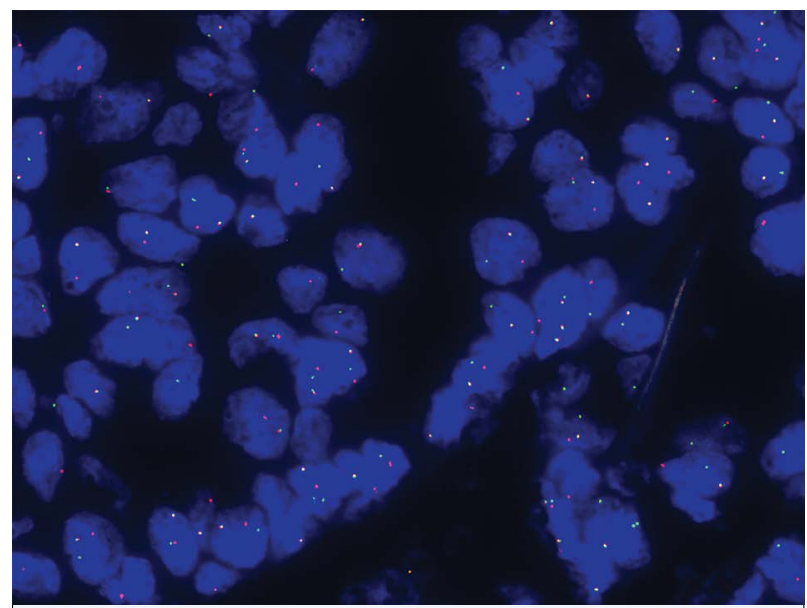

Fig. 6. ALK mutation shown by FISH method in metastatic lung carcinoma.

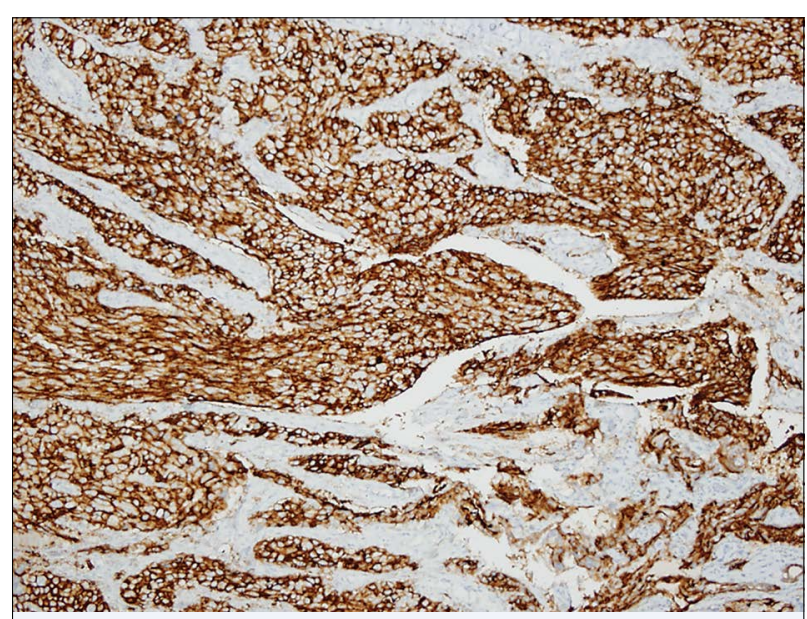

Fig. 7. Strong and diffuse immunohistochemical PDL1 expression in tumor cells.

In addition to diagnostic antigenic examinations in tumor tissue, prognostic and therapeutic markers are also investigated. Receptor analysis, presence of CerbB2 in breast carcinomas, investigation of mismatch DNA repair gene protein expression (MSH2-PMS2-MLH1MSH6) for evaluation microsatellite instability in colorectal and some other carcinomas, PCR based molecular investigations for EGFR, FISH technique for ALK (Fig. 6), ROS1, c-Met in lung carcinomas are performed routinely and widely. Again, regardless of the tumor type, PD-L1 expression is investigated immunohistochemically in tumor cells (Fig. 7) and sometimes in inflammatory cells within the scope of targeted therapies.[11]

Also, the presence of NTRK fusions can be investigated by the FISH method. Next Generation Sequenc- 
ing (NGS) has also started to be applied with different tumor panels in recent years.

However, this method should be applied with a reasonable and correct indication. How to interpret the data obtained from the examination and how it can benefit the patient in terms of prognosis and treatment should be well planned.

Since the bone tissue is very hard, decalcification should be applied to soften and cut the tissue. For the decalcification, solutions such as nitric acid, formic acid, EDTA are used. The immunohistochemical reaction though not completely may be negatively affected by decalcification process and antigen loss may occur.

Primary-directed molecular examinations may be necessary for metastatic bone tissues. For example, if lung adenocarcinoma metastasis is diagnosed in a bone biopsy, it may be required to study the treatmentoriented molecular tests used in lung adenocarcinomas from this tissue. However, it is not possible to apply molecular methods in decalcified tissues. Therefore, if possible, it is necessary to consider these possibilities immediately after receiving the biopsy and separate soft parts, if any, before decalcification.

In conclusion, bone tissue is a host to metastasis and metastatic bone tumors are much more common than the primary malignant tumors. Advanced analyses can be performed to obtain information about the primary tumor, like the origin, prognosis, and treatment, especially in those cases where histopathological examination of the primary metastatic tumor has not been performed.

\section{References}

1. Deniz K. Metastatik kemik tümörleri. In: Dervişoğlu S, Bilgiç B, Doğanavşargil B, editors. Kemik ve eklem patolojisi, multidisipliner yaklaşım. Kongre Kitabevi; 2018. p.361-78.

2. Cîrstoiu M, Munteanu O, Georgescu T, Arsene L, Sajin $\mathrm{M}$, et al. A short-term retrospective analysis of the clinical, histopathological and immunohistochemical aspects of bone metastases. Romanian J of Orthop Surg Traumatol 2019;2(2):84-90.

3. Henderson-Jackson EB, Farah K Khalil FK. Pathology of metastatic tumors to bone: effects of decalcification as experienced at a single cancer center. Oncol Cancer Case Rep 2016;2:1.

4. Tang P, Hicks DG. Histopathology of skeletal metastases. In: Heymann D, editor. Bone Cancer. $2^{\text {nd }}$ ed. Academic Press; 2014. p. 461-70.

5. WHO Classification of Tumours Editorial Board. Soft Tissue and Bone Tumours. $5^{\text {th }}$ ed. World Health Organization; 2020.

6. Fornetti J, Welm AL, Stewart SA. Understanding the bone in cancer metastasis. J Bone Miner Res. 2018;33(12):2099-2113.

7. Esposito M, Guise T, Kang Y. The biology of bone metastasis. Cold Spring Harb Perspect Med 2018 $1 ; 8(6): \mathrm{a} 031252$.

8. Zhang W, Bado I, Wang H, Ching-Lo H, Zhang XHF. Bone metastasis: find your niche and fit in. Trends Cancer 2019 Feb; 5(2): 95-110.

9. Macedo F, Ladeira K, Pinho F, Saraiva N, Bonito N, Pinto L, et al. Bone metastases: an overview. Oncol Rev 2017;11(1):321.

10. Errani C, Mavrogenis AF, Megaloikonomos PD, Antoniadou T, Antonioli D, et al. Immunohistochemical evaluation of bone metastases. Nowotwory. J Oncol 2017;67(1):1-6.

11. Bochtler T, Löffler H, Krämer A. Diagnosis and management of metastatic neoplasms with unknown primary. Semin Diagn Pathol 2018;35(3):199-206. 